\title{
A COMPARATIVE STUDY OF HAEMODYNAMIC RESPONSES TO ENDOTRACHEAL TUBE AND LARYNGEAL MASK USAGE UNDER GENERAL ANAESTHESIA
}

\author{
Kiran Madhala ${ }^{1}$, G. Naveen Kumar ${ }^{2}$ \\ ${ }^{1}$ Assistant Professor, Department of Anaesthesiology, GMC, Nizamabad. \\ ${ }^{2}$ Assistant Professor, Department of Anaesthesiology, Dr. VRK Medical College, Hyderabad, Telangana.
}

ABSTRACT
BACKGROUND
Endotracheal tube usage has become an integral part of the anaesthesiologist's contribution to the patient care. Endotracheal
intubation is translaryngeal placement of endotracheal tube into the trachea. Laryngeal mask airway insertion is an alternative to
the endotracheal intubation for maintaining airway and anaesthesia. Rapid haemodynamic changes may be harmful to the patients
with ischaemic heart disease, hypertension, cerebrovascular disease. Along with the haemodynamic responses, the placement of
the endotracheal tube and laryngeal mask airway will result in significant post-operative complications of which sore throat,
dysphonia and dysphagia are common.

Aim - Comparison of haemodynamic responses to endotracheal intubation/extubation and laryngeal mask airway insertion/removal and incidence of sore throat, dysphagia and dysphonia post-operatively.

\section{MATERIALS AND METHODS}

The study was conducted on 60 adult male patients undergoing surgery under general anaesthesia at Mahatma Gandhi Memorial Hospital, Warangal.

\section{RESULTS}

In the present study, the range for age in Group I was 19 to 42 years and in Group II was 17 to 44 years. The range for weight was 64 to $80 \mathrm{~kg}$ in Group I and 46 to 75 in Group II. The demographic data was comparable in both the groups. In both the groups, there was slight increase in heart rate, systolic blood pressure, diastolic blood pressure, mean arterial blood pressure and rate pressure product. From the standard error of difference between two means, the P value of only systolic blood pressure falls $<0.001$, so it is statistically significant. Other parameters are comparable in the two groups. In Group I, all the haemodynamic values increased significantly by $14 \%$. In Group II, the increase was by $5 \%$ which is less in comparison to Group I. The rate pressure product was near to 15,000 in Group I. The rise in parameters in Group II was low. From the standard error of difference between two means, the $\mathrm{P}$ value of all parameters fall $<0.001$, so statistically significant.

\section{CONCLUSION}

Post-operative laryngopharyngeal complaints of cough, sore throat, dysphonia incidence were more in the endotracheal tube than the Laryngeal Mask Airway. Dysphagia was more common post-operatively in the Laryngeal Mask Airway group. Laryngeal Mask Airway may be used for airway management during anaesthesia in patients in whom marked pressor response would be deleterious.

\section{KEYWORDS}

Endotracheal Tube, Laryngeal Mask Airway.

HOW TO CITE THIS ARTICLE: Madhala K, Kumar GN. A comparative study of haemodynamic responses to endotracheal tube and laryngeal mask usage under general anaesthesia. J. Evolution Med. Dent. Sci. 2017;6(8):628-632, DOI: 10.14260/Jemds/2017/135

\section{BACKGROUND}

Endotracheal tube usage has become an integral part of the anaesthesiologist's contribution to the patient care. Endotracheal intubation is translaryngeal placement of endotracheal tube into the trachea.

Laryngeal mask airway insertion is an alternative to the endotracheal intubation for maintaining airway and anaesthesia. In contrast to endotracheal intubation, laryngeal

Financial or Other, Competing Interest: None.

Submission 14-12-2016, Peer Review 12-01-2017,

Acceptance 18-01-2017, Published 25-01-2017.

Corresponding Author:

Dr. Kiran Madhala,

Assistant Professor,

Department of Anaesthesiology,

GMC, Nizamabad.

Telangana.

E-mail: drkiranmadala7@gmail.com

DOI: $10.14260 /$ jemds $/ 2017 / 135$ mask airway insertion does not require instrumentation (laryngoscopy) of the airway. Moreover, laryngeal mask airway does not pass through the glottis, but is placed over the glottis. ${ }^{1}$

Rapid and dramatic haemodynamic changes may occur during endotracheal intubation or laryngeal mask airway insertion and endotracheal tube extubation or laryngeal mask airway removal. These rapid haemodynamic changes may be harmful to the patients with ischaemic heart disease, hypertension and cerebrovascular disease. These cardiovascular responses may have disastrous consequences in the above group of patients. 2,3,4

Strategies to circumvent these changes have included minimising the duration of laryngoscopy to less than 15 seconds, use of intravenous narcotics, lignocaine, vasodilators, opioids, inhalational agents and beta blockers. Each technique has disadvantages, the most common being that the prevention often outlasts the stimulus. 
Laryngeal mask airway insertion and removal involves lesser mechanical manipulation of upper airway than endotracheal intubation and extubation.

Along with the haemodynamic responses, the placement of the endotracheal tube and laryngeal mask airway will result in significant post-operative complications, of which sore throat, dysphonia and dysphagia are common. These complications are desired to be avoided in people like professional singers. These days when the ambulatory anaesthesia has become popular, decreasing the incidence of the above-mentioned complications has gained importance.

In this study, an effort has been made to compare the haemodynamic responses to endotracheal intubation and laryngeal mask airway insertion; endotracheal extubation and laryngeal mask airway removal; and also, comparison of the incidence of the cough, sore throat, dysphonia and dysphagia on the day of surgery and on first post-operative day after endotracheal tube and laryngeal mask airway usage under general anaesthesia.

\section{Aim of Study}

- Comparison of haemodynamic responses to endotracheal intubation/extubation and laryngeal mask airway insertion/removal and incidence of sore throat, dysphagia and dysphonia post-operatively.

\section{MATERIALS AND METHODS}

The study was conducted on 60 adult male patients undergoing surgery under general anaesthesia at Mahatma Gandhi Memorial Hospital, Warangal. These patients were of age ranging from 17 to 44 years. All the patients belong to ASA Grade I. The patients undergoing general surgical procedures like Herniorrhaphy for inguinal hernia and Jaboulay's method of sac eversion for hydrocoele were selected for the study. All the patients were assessed clinically preoperatively and investigated to rule out any systemic disease.

The following investigations were carried out before subjecting the patient for surgery, namely complete blood picture, RBC, TLC, Hb\%, BT, CT, ECG, random blood sugar, blood urea, serum creatinine, blood grouping and typing, urine analysis, HIV, HBsAg and chest x-ray.

\section{Patients were divided into Two Groups Randomly}

Group I - Endotracheal tube was used.

Group II - Laryngeal mask airway was used.

\section{The Exclusion Criteria that were Adopted}

1. ASA grade more than 1.

2. Mouth opening adequate, more than 3 finger breadths.

3. Mallampati Grading (MPG), more than 1.

4. Regurgitation prone conditions.

5. Attempts of insertion, more than 1.

6. Duration of insertion, more than 1.

7. Initial bradycardia and hypotension.

8. Treatment with beta blockers or calcium channel blockers.

9. Significant systemic disease like diabetes, hypertension.

10. Morbid obesity and GERD.
During the study patient's heart rate, systolic blood pressure, diastolic blood pressure and mean arterial blood pressure were recorded and rate pressure product was calculated during the following periods.

\section{During Endotracheal Intubation/Laryngeal Mask Airway Insertion}

1. Preoperative (initial recording).

2. Induction (baseline value).

3. 1 minute after intubation/insertion.

4. 3 minutes after intubation/insertion.

5. 5 minutes after intubation/insertion.

\section{During Endotracheal Extubation/Laryngeal Mask} Removal

1. Baseline value.

2. 1 minute after extubation/removal.

3. 3 minutes after extubation/removal.

4. 5 minutes after extubation/removal.

And also the incidence of cough, sore throat, dysphagia and dysphonia were noted on the day of surgery and first post-operative day by interview method.

\section{RESULTS}

\begin{tabular}{|c|c|c|}
\hline Demographic Data & Age (Years) & Weight (kg) \\
\hline $\begin{array}{c}\text { Group-I } \\
\text { Endotracheal tube) } \\
(\mathrm{n}=30)\end{array}$ & $29(19-42)$ & $68.5(64-80)$ \\
\hline $\begin{array}{c}\text { Group-II } \\
\left(\begin{array}{c}\text { Laryngeal mask airway) } \\
(\mathrm{n}=30)\end{array}\right.\end{array}$ & $31(17-44)$ & $63.3(46-75)$ \\
\hline \multicolumn{2}{|c|}{ Table 1. Demographic Data } \\
\hline
\end{tabular}

Table showing age and weight distribution in both the groups. The range for age in Group I was 19 to 42 years and in Group II was 17 to 44 years. The range for weight was 64 to $80 \mathrm{~kg}$ in Group I and 46 to 75 in Group II. The demographic data was comparable in both the groups.

\begin{tabular}{|l|c|c|c|}
\hline & Group I & Group II & A \\
\hline HR & $87.6( \pm 7.8)$ & $87.5( \pm 10.75)$ & 2.42 \\
\hline SBP & $121.6( \pm 7.2)$ & $109( \pm 15.75)$ & 2.58 \\
\hline DBP & $78.2( \pm 6.2)$ & $80.1( \pm 5.09)$ & 1.46 \\
\hline MAP & $89.4( \pm 5.6)$ & $87.6( \pm 7.33)$ & 1.68 \\
\hline RPP & 10641.1 & 10660.6 & \\
\hline \multicolumn{4}{|l|}{ Table 2. Haemodynamic Parameters at Induction } \\
\hline
\end{tabular}

In both the groups there was slight increase in heart rate, systolic blood pressure, diastolic blood pressure, mean arterial blood pressure and rate pressure product. From the standard error of difference between two means, the P value of only systolic blood pressure falls $<0.001$, so it is statistically significant. The other parameters are comparable in the two groups. 


\begin{tabular}{|c|c|c|c|}
\hline & Group I & Group II & A \\
\hline HR & $115.2( \pm 9.7)$ & $96.2( \pm 11.24)$ & 1.76 \\
\hline SBP & $139.2( \pm 7.3)$ & $123.1( \pm 13.4)$ & 2.78 \\
\hline DBP $)$ & $89.2( \pm 6.5)$ & $84.6( \pm 5.51$ & 1.55 \\
\hline MAP & $105.8( \pm 6.3)$ & $98.36( \pm 7.7)$ & 1.81 \\
\hline RPP & 16150.1 & 11808.3 & \\
\hline \multicolumn{3}{|c|}{$\begin{array}{l}\text { Table 3. Haemodynamic Parameters at One Minute } \\
\text { (Endotracheal Intubation/Laryngeal Mask Airway } \\
\text { Insertion) }\end{array}$} \\
\hline
\end{tabular}

From the standard error of difference between two means, $\mathrm{P}$ values of all parameters fall $<0.001$, so they are statistically highly significant.

(Endotracheal Intubation/Laryngeal Mask Airway Insertion)

\begin{tabular}{|c|c|c|c|}
\hline & Group I & Group II & A \\
\hline HR & $100.5( \pm 12.9)$ & $93.7( \pm 9.5)$ & 2.9 \\
\hline SBP & $127.7( \pm 5.5)$ & $120.4( \pm 12.8)$ & 2.54 \\
\hline DBP & $85.5( \pm 6.2)$ & $83.3( \pm 5.2)$ & 1.48 \\
\hline MAP & $97.8( \pm 6.1)$ & $95.8( \pm 7.3)$ & 1.73 \\
\hline RPP & 14290.8 & 11340.9 & \\
\hline Table 4. Haemodynamic Parameters at Three Minutes \\
\hline
\end{tabular}

The parameters were still significantly higher than baseline in the Group I. The values in the Group II were nearing the baseline recordings. From the standard error of difference between two means, the $P$ value of heart rate and systolic blood pressure fall $<0.001$, so statistically significant.

\section{Endotracheal Intubation/Laryngeal Mask Airway} Insertion

\begin{tabular}{|c|c|c|c|}
\hline & Group I & Group II & A \\
\hline HR & $92( \pm 9.4)$ & $90.6( \pm 10.5)$ & 2.5 \\
\hline SBP & $124.2( \pm 11.1)$ & $117.6( \pm 15.6)$ & 3.8 \\
\hline DBP & $81.4( \pm 6.6)$ & $81.6( \pm 4.8)$ & 2.21 \\
\hline MAP & $95.52( \pm 5.9)$ & $93.8( \pm 6.8)$ & 1.07 \\
\hline RPP & 12232.4 & 10737.4 & \\
\hline \multicolumn{4}{|c|}{ Table 5. Haemodynamic Parameters at Five Minutes } \\
\hline
\end{tabular}

The values were almost near to the baseline values in Group II and the values of Group I were still remaining more higher than baseline values. From the standard error of difference between two means, the $\mathrm{P}$ values of systolic blood pressure and mean arterial blood pressure fall $<0.001$, so statistically significant.

Endotracheal Extubation/Laryngeal Mask Airway Removal

\begin{tabular}{|l|c|c|c|}
\hline & Group I & Group II & A \\
\hline HR & $110.4( \pm 8.5)$ & $92.6( \pm 10.7)$ & 2.4 \\
\hline SBP & $134.8( \pm 6.8)$ & $122.3( \pm 12.3)$ & 2.5 \\
\hline DBP & $87.5( \pm 6.5)$ & $84.8( \pm 5.01)$ & 1.49 \\
\hline MAP & $103.4( \pm 5.3)$ & $97.3( \pm 6.2)$ & 1.48 \\
\hline RPP & 14412.3 & 11753.8 & \\
\hline \multicolumn{4}{|l}{ Table 6. Haemodynamic Parameters at 1 Minute } \\
\hline
\end{tabular}

In Group I, all the haemodynamic values increased significantly by $14 \%$. In Group II, the increase was by $5 \%$ which is less in comparison to Group I. The rate pressure product was near to 15,000 in Group I. The rise in parameters in Group II was low. From the standard error of difference between two means, the $\mathrm{P}$ value of all parameters fall $<0.001$, so statistically significant.

Endotracheal Extubation/Laryngeal Mask Airway Removal

\begin{tabular}{|c|c|c|c|}
\hline & Group I & Group II & A \\
\hline HR & $104.2( \pm 6.9)$ & $92( \pm 8.7)$ & 1.25 \\
\hline SBP & $128.6( \pm 6.7)$ & $120.8( \pm 11.8)$. & 1.2 \\
\hline DBP & $84.3( \pm 6.6)$ & $83.5( \pm 5.4)$ & 1.1 \\
\hline MAP & $98.7( \pm 4.2)$ & $95.8( \pm 6.7)$ & 0.76 \\
\hline RPP & 13407.3 & 11082 & \\
\hline \multicolumn{4}{|l}{ Table 7. Haemodynamic Parameters at 3 Minutes } \\
\hline
\end{tabular}

The parameters in Group II were almost near to the baseline values compared to Group I value, which were still high. From the standard error of differences between the two means, the $P$ values of heart rate, systolic blood pressure and mean arterial blood pressure fall $<0.001$, so they are statistically significant.

Endotracheal Extubation/Laryngeal Mask Airway Removal

\begin{tabular}{|c|c|c|c|}
\hline & Group I & Group II & A \\
\hline HR & $96.2( \pm 6.7)$ & $90( \pm 8.4)$ & 1.93 \\
\hline SBP & $123.3( \pm 6.5)$ & $114( \pm 12.6)$ & 2.5 \\
\hline DBP & $82.25( \pm 5.9)$ & $82.6( \pm 4.6)$ & 1.07 \\
\hline MAP & $95.5( \pm 4.8)$ & $94.6( \pm 6.7)$ & 0.87 \\
\hline RPP & 11990.4 & 10713.5 & \\
\hline \multicolumn{4}{|l}{ Table 8. Haemodynamic Parameters at 5 Minutes } \\
\hline
\end{tabular}

The values in the Group II almost touched the baseline compared to the Group I, which were still high. From the standard error of difference between two means, $\mathrm{P}$ value of heart rate and systolic blood pressure falls $<0.001$, so statistically significant.

\begin{tabular}{|c|c|c|}
\hline & Group I & Group II \\
\hline Cough & $15(50 \%)$ & $10(33.3 \%)$ \\
\hline Sore Throat & $14(46.6 \%)$ & $10(33.3 \%)$ \\
\hline Dysphonia & $15(50 \%)$ & $8(26.6 \%)$ \\
\hline Dysphagia & $4(13.3 \%)$ & $8(26.6 \%)$ \\
\hline $\begin{array}{c}\text { Table 9. Postoperative Incidence of Cough, Sore Throat, } \\
\text { Dysphonia and Dysphagia (On the Day of Surgery) }\end{array}$ \\
\hline
\end{tabular}

The incidence of cough, sore throat and dysphonia were recorded high in the Group I. Dysphagia was recorded high in the Group II.

\section{DISCUSSION}

The laryngoscopy and endotracheal tube usage may provoke a marked haemodynamic response. This may have insignificant effects in a young healthy individual, but this may have disastrous consequences in certain patient population including those with coronary artery disease, systemic arterial hypertension, aneurysmal vascular disease and increased intracranial pressure. 
The Laryngoscopy results in stimulation of pharyngeal wall and causes marked haemodynamic changes. Endotracheal tube passes through the glottis and provides a continuous stimulus in the glottis for provocation of haemodynamic response. An inflated endotracheal tube cuff does the same.

The insertion of Laryngeal Mask Airway avoids laryngoscopy. It does not pass through glottis, rather sits above the glottis. Moreover, Laryngeal Mask Airway insertion too causes haemodynamic response. When the Laryngeal Mask Airway cuff is inflated, it stimulates the pharyngeal wall. But this stimulation is transient and subsides sooner than that caused by an inflated endotracheal tube cuff.

The stimulation of mechanoreceptors in the pharyngeal wall, epiglottis and vocal cords is thought to be the cause for this reflex haemodynamic.

In our study, we tried to compare the haemodynamic response for Laryngeal Mask Airway insertion and laryngoscopy and endotracheal intubation. In 60, ASA Grade I patients undergoing surgery, randomly divided, we inserted Laryngeal Mask Airway in 30 patients and intubated in 30 patients. We recorded the haemodynamic parameters namely heart rate, systolic blood pressure, diastolic blood pressure, mean arterial blood pressure and calculated rate pressure product at pre-operative induction, 1 minute, 3 minute and 5 minute periods after endotracheal tube intubation and laryngeal mask airway insertion.

The pre-operative values in both the groups were comparable and there was no statistically significant difference between them

Following induction with Thiopentone there was a slight increase in the heart rate, systolic and diastolic blood pressures.

The haemodynamic parameters were found to increase markedly by $18 \%$ in endotracheal tube intubation and by $9 \%$ in laryngeal mask airway insertion at 1 minute after Laryngeal Mask Airway insertion or endotracheal tube intubation in both the groups. Observation at 3 minutes after intubation/insertion showed that the values in Group I were statistically significant higher than those in Group II. The values in Group II were almost close to baseline values.

Observation at 5 minutes after intubation/insertion showed the values returning to baseline values in Group II and still remaining high in Group I.

Wilson I G; Robinson S L et $\mathrm{al}^{5}$ in 1992 compared cardiovascular responses to insertion to Laryngeal Mask Airway and endotracheal intubation. They found that the mean maximum increase in systolic blood pressures after laryngoscopy and endotracheal intubation was 51.3\% compared with $22.9 \%$ for Laryngeal Mask Airway insertion. Increase in maximum heart rate was $26.6 \%$ for endotracheal tube and $25.7 \%$ for Laryngeal Mask Airway. Heart rate remained elevated for a longer period with endotracheal tube. They concluded that insertion of the Laryngeal Mask Airway is accompanied by smaller cardiovascular responses than those after laryngoscopy and intubation.

Wood M J and Forrest E T et $\mathrm{al}^{6}$ in 1984 compared the haemodynamic response to the insertion of Laryngeal Mask Airway to that of the laryngoscopy and endotracheal intubation. The changes in all cardiovascular parameters measured the following Laryngeal Mask Airway were less when compared with those following endotracheal intubation.

Fujii Y, Tanaka H, Toyooka $\mathrm{H}_{\text {et }} \mathrm{al}^{7}$ in 1995 , studied the effects of Laryngeal Mask Airway insertion and endotracheal intubation on circulatory responses. They found that the haemodynamic changes were greater after intubation than after Laryngeal Mask Airway insertion. They concluded that insertion of Laryngeal Mask Airway is associated with less circulatory responses.

The results of the present study are consistent with the above studies, in that haemodynamic responses to Laryngeal Mask Airway insertion are less than to that of endotracheal intubation.

Likewise, cardiovascular changes during Laryngeal Mask Airway removal were recorded less than the haemodynamic responses to tracheal extubation. During and after tracheal extubation, plasma concentration of catecholamines, such as noradrenaline and adrenaline is increased. The precise mechanism responsible for increase in the heart rate and hypertension after tracheal extubation is not known, but these haemodynamic changes may be associated with the release of catecholamines during this period. The less catecholamine release in the Laryngeal Mask Airway group will result in less heart rate and hypertensive response.

Tracheal extubation irritates airway causing coughing, which is known to increase heart rate and blood pressure. This is based on the observation that coughing leads to increase in intrathoracic pressure, which interferes with the venous return to heart.

In this study, the number of patients who experienced cough was less in Laryngeal Mask Airway group. Therefore, it is suggested that Laryngeal Mask Airway removal may attenuate laryngeal irritation.

We in the study also recorded haemodynamic parameters namely heart rate, systolic blood pressure, diastolic blood pressure, mean arterial blood pressure and calculated rate pressure product at the end of surgery just before endotracheal extubation/removal of the Laryngeal Mask Airway and also at 1, 3 and 5 minutes immediately after the procedure. Minimal pharyngeal suction was allowed.

The haemodynamic parameters were found to be increased to 1 minute after endotracheal tube extubation and Laryngeal Mask Airway removal. But the increase in the parameters in Laryngeal Mask Airway removal were less than that of endotracheal tube $14 \%$ in endotracheal tube and $5 \%$ in laryngeal mask airway). The rate pressure product was also significantly higher.

Observation at 3 minutes after extubation/removal showed that the values in endotracheal tube extubation were still higher than those on Laryngeal Mask Airway removal. The values in Laryngeal Mask Airway removal were almost near to the baseline values.

Observation at 5 minutes after extubation/removal showed the values returned to the basal values in Laryngeal Mask Airway removal, but remaining higher in endotracheal tube extubation.

Braude N, EA Clements, et al ${ }^{8}$ in 1989 compared the pressor response to Laryngeal Mask Airway insertion with tracheal intubation. They found statistically significant differences only in case of diastolic blood pressures at 1 minute and 3 minutes after intubation/insertion. They 
however reported an attenuated pattern of pressor response with Laryngeal Mask Airway insertion.

The results of the present study are consistent with the above studies, in that haemodynamic responses to Laryngeal Mask Airway insertion are less than to that of endotracheal intubation.

Fujii; Toyooka; Hidenori et al ${ }^{7}$ in 1995 also studied cardiovascular responses to tracheal extubation or Laryngeal Mask Airway removal in normotensive and hypertensive patients. They found that in normotensives, the haemodynamic parameters increased following tracheal extubation or Laryngeal Mask Airway removal and remained elevated for $3 \mathrm{~mm}$ and degrees of elevation was more with tracheal extubation than Laryngeal Mask Airway. The degree of the changes was more in the hypertensives and the parameters remained elevated for about 5 minutes.

The results of the present study were consistent with the above studies and the haemodynamic response were less in the Laryngeal Mask Airway group than the endotracheal tube group.

Post-operative sore throat following anaesthesia using endotracheal tube or Laryngeal Mask Airway is multifactorial. The common factors are the depth of the anaesthesia at the time of insertion, method of insertion, number of attempts used for the placement; the general factors included sex (more common in females), age (increased incidence in young) and duration of anaesthesia (prolonged duration increases the sore throat). In endotracheal tube placement, the laryngoscopy procedure itself and associated pressure effect of the presence of the tube in pharynx and mouth cavity will also cater to the increased incidence of the sore throat. The hypothesis that concomitant decrease in pharyngeal perfusion due to pressure from the cuff might lead to some incidence of sore throat in the Laryngeal Mask Airway group.

The Laryngeal Mask Airway does not traverse the vocal cords and hence the dysphonia and cough are less than induced by tracheal intubation. This accounts for recommendation of Laryngeal Mask Airway in professional singers. The direct contact of Laryngeal Mask Airway with arytenoid cartilage may cater to dysphonia in some cases. In intermittent positive pressure ventilation, the vocal cords, would have received impacts from intermittent flow of gases from the machine and microtraumas leading to dysphonia.

The placement of the Laryngeal Mask Airway in the pharynx and pressure effect on the pharynx will usually result in increased incidence of dysphagia in Laryngeal Mask Airway group than endotracheal tube group and also, increased incidence of gastric reflux activity in Laryngeal Mask Airway group may also be an additional factor.

In our study the incidence of cough, sore throat and dysphonia were significantly higher in endotracheal tube on the day of surgery and first post-operative day. The dysphagia was seen in more incidence in laryngeal mask airway group on both days.

Lee, Hong, Choe, Song et $\mathrm{al}^{9}$ in 1989 compared the changes in vocal function produced after Laryngeal Mask Airway and endotracheal tube usage with the help of acoustic waveform analysis and found Laryngeal Mask Airway causing less change in the variables.

Romaniuk, Jalowiecki, Krawczyk et al10 evaluated the usefulness of Laryngeal Mask Airway comparing with the endotracheal tube in eye surgery and found a greater incidence of coughing, stridor and sore throat in the tracheal tube group. The results of the present study are consistent with above studies in that the incidence of cough, sore throat and dysphonia were more in the endotracheal tube group, but the dysphagia was found more in the Laryngeal Mask Airway group.

\section{CONCLUSION}

- Haemodynamic response to Laryngeal Mask Airway insertion/removal is much less than that of endotracheal tube intubation/extubation.

- Haemodynamic response to Laryngeal Mask Airway insertion/removal is not only attenuated, but also transient.

- No untoward incidents occurred with airway management by Laryngeal Mask Airway.

- Post-operative laryngopharyngeal complaints of cough, sore throat and dysphonia incidence were more in the endotracheal tube than the Laryngeal Mask Airway.

- Dysphagia was more common post-operatively in the Laryngeal Mask Airway group.

- Laryngeal Mask Airway may be used for airway management during anaesthesia in patients in whom marked pressor response would be deleterious.

\section{REFERENCES}

[1] Leach AB, Alexander CA. The laryngeal mask--an overview. European Journal of Anaesthesiology Supplement 1991;4:19-31.

[2] King BD, Harris LC Jr, Greifenstein FE, et al. Reflex circulatory responses to direct laryngoscopy and tracheal intubation performed during general anesthesia. Anesthesiology 1951;12(5):556-66.

[3] Prys-Roberts C, Greene LT, Meloche P. Studies of anaesthesia in relation to hypertension. ii. Haemodynamic consequences of induction and endotracheal intubation. Br J Anaesth 1971;43(6):53147.

[4] WYCOFF CC. Endotracheal intubation: effects on blood pressure and pulse rate. Anesthesiology 1960;21(3):153-8.

[5] Wilson IG, Fell D, Robinson SL, et al. Cardiovascular responses to insertion of the laryngeal mask. Anaesthesia 1992;47(4):300-2.

[6] Wood ML, Forrest ET. The haemodynamic response to the insertion of the laryngeal mask airway: a comparison with laryngoscopy and tracheal intubation. Acta Anaesthesiol Scand 1994;38(5):510-3.

[7] Fujii Y, Tanaka H, Toyooka H. Circulatory responses to laryngeal mask airway insertion or tracheal intubation in normotensive and hypertensive patients. Can J Anaesth 1995;42(1):32-6.

[8] Braude N, Clements EA, Hodges UM, et al. The pressor response and laryngeal mask insertion. A comparison with tracheal intubation. Anaesthesia 1989;44(7):551-4.

[9] Lee JJ. Laryngeal mask and trauma to uvula. Anaesthesia 1989;44(12):1014-5.

[10] Poloch A, Romaniuk W, Jałowiecki P, et ál. Evaluation of the usefulness of the laryngeal mask for general anesthesia in eye microsurgery--preliminary results. Klin Oczna 1996;98(1):45-9. 